\title{
Removal of organic pollutants from produced water by batch adsorption treatment
}

\author{
Eman Hashim Khader ${ }^{1} \cdot$ Thamer Jassim Mohammed $^{1} \cdot$ Nourollah Mirghaffari $^{1} \cdot$ Ali Dawood Salman ${ }^{1,2}$ (D) \\ Tatjána Juzsakova ${ }^{1} \cdot$ Thamer Adnan Abdullah $^{1}$
}

Received: 17 November 2020 / Accepted: 8 July 2021 / Published online: 25 August 2021

(c) The Author(s) 2021

\begin{abstract}
This paper studied the adsorption of chemical oxygen demand (COD), oil and turbidity of the produced water (PW) which accompanies the production and reconnaissance of oil after treating utilizing powdered activated carbon (PAC), clinoptilolite natural zeolite (CNZ) and synthetic zeolite type X (XSZ). Moreover, the paper deals with the comparison of pollutant removal over different adsorbents. Adsorption was executed in a batch adsorption system. The effects of adsorbent dosage, time, $\mathrm{pH}$, oil concentration and temperature were studied in order to find the best operating conditions. The adsorption isotherm models of Langmuir, Freundlich and Temkin were investigated. Using pseudo-first-order and pseudo-second-order kinetic models, the kinetics of oil sorption and the shift in COD content on PAC and CNZ were investigated. At a PAC adsorbent dose of $0.25 \mathrm{~g} / 100 \mathrm{~mL}$, maximum oil removal efficiencies (99.57, 95.87 and 99.84 percent), COD and total petroleum hydrocarbon (TPH) were identified. Moreover, when zeolite $X$ was used at a concentration of $0.25 \mathrm{~g} / 100 \mathrm{~mL}$, the highest turbidity removal efficiency (99.97\%) was achieved. It is not dissimilar to what you would get with PAC (99.65 percent). In comparison with zeolites, the findings showed that adsorption over PAC is the most powerful method for removing organic contaminants from PW. In addition, recycling of the consumed adsorbents was carried out in this study to see whether the adsorbents could be reused. Chemical and thermal treatment will effectively regenerate and reuse powdered activated carbon and zeolites that have been eaten.
\end{abstract}

\section{Graphic abstract}
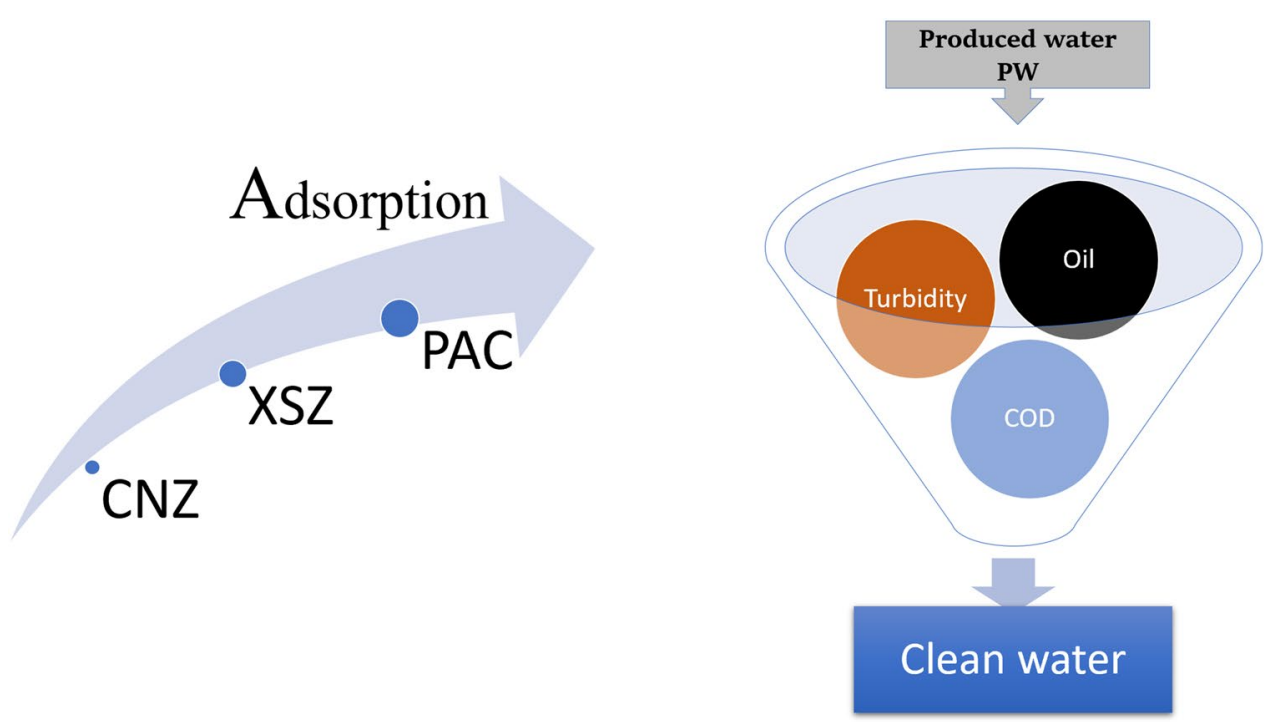

Keywords Activated carbon · Adsorption $\cdot$ Chemical oxygen demand $\cdot$ Oil $\cdot$ Produced water $\cdot$ Zeolites

Extended author information available on the last page of the article 


\section{Abbreviations \\ CNZ Clinoptilolite natural zeolite \\ COD Chemical oxygen demand \\ PAC Powdered activated carbon \\ PW Produced water \\ TDS Total dissolved solid \\ TPH Total petroleum hydrocarbon \\ WHO Word Health Organization \\ XSZ Synthetic zeolite type X}

\section{Introduction}

Produced water (PW) is the largest stream of wastewater generated by the petroleum industry during oil and gas field exploration and production and contains a wide range of hydrocarbons in free, dispersed and dissolved forms (AlGhouti et al. 2019). PW has a complex compound (organic and inorganic), such as grease, dissolved and dispersed oil, formation solids, scale products, heavy metals, waxes, radionuclides, dissolved oxygen, treating chemicals, dissolved gases, salts and microorganisms (Igunnu and Chen 2014). 250 million barrels of water per day is generated from gas and oil fields, and greater than $40 \%$ of it is discharged to the environment globally (Hedar 2018), the discharge of PW may lead to severe pollution of surface, soil and underground water, and the hazard comes from the absence of appropriate treatment. Therefore, many technologies for the purification of PW are utilized (Show 2021) and can be divided into biological, chemical or physical methods (Fakhru'l-Razi 2009). Microbial degradation (Quintana et al. 2005), filtration (Guo et al. 2018), chemical oxidation (Zhu et al. 2020), electrochemical oxidation (Nidheesh et al. 2020), coagulation (Khader et al. 2018) and membrane separation (Xiao et al. 2010) may be suitable technologies for the elimination of environmental pollution. However, these techniques have their own limitations such as high cost, generation of secondary pollutants and poor removal efficiency (Gupta et al. 2012; Han 2007). Adsorption is considered the most significant traditional techniques for purification and reclamation of produced water (Zhao 2015), including the elimination of biological, organic and inorganic pollutants that are insoluble and soluble in water for meeting the environmental standards at least cost (Rashed 2013), so has been introduced as an environmental-friendly and cost-effective and economic method. It can replace other conventional methods for the treatment of pollutants in the wastewater (Kim et al. 2018; Albayati et al. 2020). Hence, it can be utilized in a wide range of applications and gives the removal efficiency over to $99 \%$, ease of separation of the targeted compounds from the dilute solution, simplicity of design and operation, insensitive to toxic materials and the possibility of recovery of the adsorbed materials easily by different methods (desorbing agents, leaching employing chemical reagents, biological processes and thermal treatment) (Alardhi et al. 2020).

In the adsorption process, several types of adsorbents such as activated carbons, zeolites, activated alumina or low-cost materials (limestone, rice husk ash, peat, etc.) can be used. Activated carbon is considered the most widely used adsorbent (Babel and Kurniawan 2003). AC is an amorphous, microcrystalline and non-graphical solid with certain properties, including high thermal stability, high light stability, porous and solid structure, high mechanical stability, a high surface-to-volume ratio and high pureness. Furthermore, since $\mathrm{AC}$ has a high capacity for adsorption of various species, it can be used as an adsorbent to remove ions and organic contaminants from wastewater (Jhadhav 2015).

Because of their cost-effectiveness, zeolites are one of the most widely used adsorbents in water treatment (Pandey et al. 2020). Natural zeolites are mineral crystalline aluminosilicates and hydrated alkali and alkaline earth metals with a tridimensional lattice that are divided into two types (clinoptilolite, analcime, limonite, phillipsite, mordenite) and artificial zeolites (Malekmohammadi et al. 2016). Clinoptilolite is the most abundant of the more than 40 natural zeolite species, and its low cost, high specific surface area and high ion exchange capability make it a popular choice for water and wastewater treatment (Hamidpour et al. 2010; Yang et al. 2011). The synthetic zeolites are usually obtained from the chemical reaction between sodium silicate, $\mathrm{Na}_{2} \mathrm{SiO}_{3}$, and sodium aluminate, $\mathrm{NaAlO}_{2}$, under varying conditions of temperature, pressure and reaction time. Raw materials such as fly ash, perlite, clay minerals and obsidian, in addition to pure chemical reagents, can be used in the synthesis of zeolites (Bandura et al. 2017).

Some researchers studied the ability the AC and zeolites (natural and synthetic) in the treatment of pollutants from wastewater. Pandey et al. (2020) applied the clinoptilolite zeolite, molybdenum sulfide $\left(\mathrm{MoS}_{2}\right)$ and $\mathrm{MoS}_{2}$-clinoptilolite composite to treat lead $(\mathrm{Pb})$ in industrial mining wastewater. Al-Haddad et al. (2007) used the natural zeolite (clinoptilolite), manufactured synthetic zeolite and activated carbon to treat ammonia from refinery wastewater. Payne and Abdel-Fattah 2004 compared and evaluated the performance of activated carbon and natural zeolites (clinoptilolite and chabazite) and synthetic zeolites (Faujasite (13X) and Linde type $\mathrm{A}(5 \mathrm{~A})$ in the treatment of $\mathrm{Pb} 2+$ by using batch adsorption. Bandura et al. (2016) utilized synthetic zeolites (Na-P1 and $\mathrm{Na}-\mathrm{X}$ ) and natural zeolites (clinoptilolite and diatomite) to reduce (Benzene, Toluene, Xylene) BTX from gas streams. Malekmohammadi et al. (2016) studied the efficiency of adsorbents (zeolite, silica and activated carbon) in the treatment of pollutants (COD, phosphate, iron, ammonium and turbidity). Vega et al. (2018) applied the faujasite zeolite type $\mathrm{X}$ to remove heavy metals, water hardness, 
ammoniacal nitrogen and COD. Daoud (2020) evaluated the ability mixture of natural zeolite and granular activated carbon in treatment of $\mathrm{Fe}, \mathrm{Cu}, \mathrm{Zn}$ and $\mathrm{Pb}$ from landfill leachatecontaminated groundwater. Paliulis (2016) tested the chemically modified and natural zeolite consisting of mordenite and clinoptilolite minerals in the reduction of formaldehyde by the adsorption process. El-Naas et al. (2010) evaluated the performance of locally prepared date-pit activated carbon for the removal of COD from petroleum refinery wastewater. Malik (2004) used the mahogany sawdust to develop carbon adsorbent for the reduction of direct dyes from textile wastewater. Nekoo and Fatemi (2013) employed Granular activated carbon for the removal of COD. However, there is no researcher appearing the simultaneous treatment of oil content, COD, TPH contents and turbidity in produced water by unmodified activated carbon and zeolites (natural and synthetic).

The aim of this study is to investigate the ability of several adsorbents (activated carbon, natural zeolites and synthetic zeolite type $\mathrm{X}$ ) and the comparison between them in the treatment of produced water (removal of oil content, COD, TPH contents and turbidity). The reduction of these contaminated is necessary to meet the requirements set by the Iraqi Central Organization for Standardization and Quality Control and World Health Organization (WHO). In addition, the adsorption kinetics, isotherm behaviors were studied and the thermodynamic parameters were calculated as well.

\section{Materials and methods}

\section{Materials}

Natural zeolite (clinoptilolite) utilizing in this work was supplied from Atcholding Company Iran, and powdered activated carbon and synthetic zeolite type $X$ were purchased from Sigma-Aldrich Company. Before carrying out the experiments, the two types of zeolite were washed several time with distilled water and then dried in an oven at $110^{\circ} \mathrm{C}$ for $24 \mathrm{~h}$. Sodium hydroxide $[\mathrm{NaOH}$, purity $\geq 97 \%$ ] and hydrochloric acid ( $\mathrm{HCl}$, purity $\geq 98 \%$ )] were obtained from Sigma-Aldrich Company. The crude oil (light oil) and clay (bentonite) were supplied from the Petroleum Research and Development Center in the Oil Ministry of Iraq. The X-ray fluorescence method was utilized to determine the chemical composition of adsorbents, and the Brunauer-Emmet-Teller method was used to determine the surface area of the adsorbents. The values of other properties were determined as well, and the results are summarized in Table S1.

\section{Synthetic produced water}

Chemicals were added to $1000 \mathrm{~mL}$ distilled water, such as clay materials (bentonite $4 \mathrm{~g}$ ), crude oil (light oil $0.1 \mathrm{~g}$ ) and salt $(\mathrm{NaCl} 100 \mathrm{~g})$, to prepare the synthetic produced water in order to adjust the properties of the PW for this research. The oil value and synthetic PW turbidity were set to become equivalent to the parameters (oil content, turbidity and salt content) of the natural PW which was taken from the Southern Oil Company in Basra, Iraq. The light oil and bentonite were mixed with distilled water by stirred for $15 \mathrm{~min}$ at high speed $(27,000 \mathrm{rpm})$ to obtain a regular diffusion of light oil and bentonite. The characteristics of the synthetic PW utilized in this research are summarized in Table S2.

\section{Batch adsorption methods}

The experiments of batch adsorption were executed in a 150$\mathrm{ml}$ conical glass flask filled with $100 \mathrm{ml} \mathrm{PW}$, and $0.03-0.3 \mathrm{~g}$ adsorbents were added to the water. The glass flask was placed onto a mechanistic shaker instrument (Water Bath Shaker Heidolph Unimax 1010 model) used to mix the PW with adsorbents and set at $200 \mathrm{rpm}$ speed. In order to follow the concentration of the residual pollutant, the sample withdrawn by pipette and then put in a centrifugal instrument for $10 \mathrm{~min}$ at $4500 \mathrm{rpm}$. Then, the adsorbent was separated from the sorbate. Figure 1 shows a schematic view of an experimental apparatus including the shaker water bath model (WisdBath) and centrifuge.

The pollutants remaining in the treated water were analyzed by using special analytical instruments for each pollutants using (Oil Content Analyzer) HORIBA instrument model OCMA-350 to measure oil content in PW. The turbidity meter that used in the measurements of the samples turbidities during the experiments was Lovibond Turb Direct model/serial number12/1805 with a measurement unit NTU (nephlometric turbidity unit), and COD was measured by using COD instrument model Lovibond SN11/25370. Adsorption time ranged from 10 to $90 \mathrm{~min}$ and the $\mathrm{pH}$ range was $2-10$. The $\mathrm{pH}$ meter used in this work allows measuring $\mathrm{pH}, \mathrm{EC}$ (conductivity) and TDS (model MW801). Various concentrations of oil $\left(C_{o}=50-1000 \mathrm{ppm}\right)$ and $\operatorname{COD}\left(C_{o}=1357-26,890 \mathrm{ppm}\right)$ at $25^{\circ} \mathrm{C}$ were applied to studied the adsorption isotherm models. And the range of temperature from 10 to $55{ }^{\circ} \mathrm{C}$ was applied to conduct the adsorption experiments thermodynamic. The percentage of removal efficiency and the amount of pollutant adsorbed by the adsorbents were calculated by the following equations:

Removal $\%=\frac{(C o-C e)}{C o} \times 100$ 


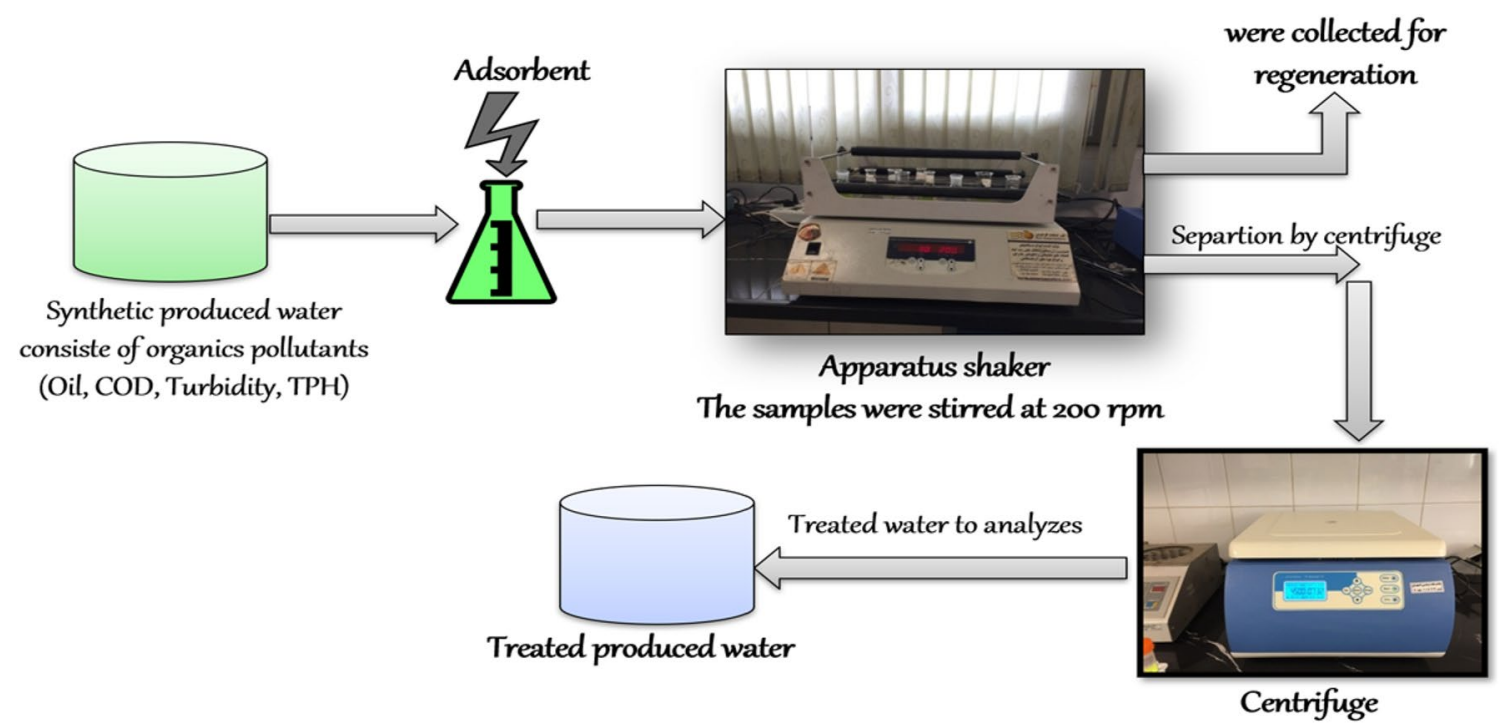

Fig. 1 Schematic view of an experimental apparatus

$q_{e}=\frac{(C o-C e) \times V}{m}$

where $C_{o}$ and $C_{e}$ are the initial and equilibrium concentrations of pollutants in PW, respectively; $q_{e}$ is the amount of pollutant adsorbed at equilibrium, $V$ is the volume of solution and $m$ is the mass of the adsorbents utilized.

\section{Results and discussion}

The effects of adsorbents dose on the oil, COD removal efficiencies and decrease in turbidity are illustrated in Figure S1. As shown, the removal efficiency increases with an increase in the adsorbent dose up to $0.25 \mathrm{~g}$. This can be explained by the introduction of more binding/sorption sites and larger specific surface area. However, further increase in the dose of adsorbent $(>0.25 \mathrm{~g}$ ) does not result in additional removal, and it remains almost constant or decreasing, which could be attributed to saturation of the binding sites (Mohan and Gandhimathi 2009). The initial oil and COD concentrations of the PW were $100 \mathrm{ppm}$ and $2508 \mathrm{ppm}$, respectively. Depending on dosage addition studies, it was discovered that using 0.03-0.3 g/100 mL PAC and CNZ at $\mathrm{pH}=7$, for $30 \mathrm{~min}$, it is capable of adsorbing up to 87.2 percent of the initial oil content, $79.1 \%$ of the initial COD content and 98.15 percent of the initial turbidity (at $0.3 \mathrm{~g}$ PAC dose $/ 100 \mathrm{~mL}$ ). At $0.3 \mathrm{~g}$ $\mathrm{CNZ}$ dose/100 $\mathrm{mL}$ addition, the removal efficiency reached up to $74.6 \%$ for the oil, $49.92 \%$ for the COD and $98.85 \%$ for the turbidity.

At 100 ppm oil concentration and 1357 ppm COD concentration, the effect of time on the adsorption of pollutants (oil, COD and turbidity) by PAC and CNZ was studied, and the results are shown in Figure $\mathrm{S} 2$.

Figure S2 shows that the removal efficiency increasing with increased time and the adsorption included two important phases; the primary quick uptake phase was followed by a relatively slow uptake phase before reached to equilibrium. This can be explained due to the availability of a large number of vacant surface sites for adsorption, but with increased time, fewer available sites on the adsorbent surface for adsorption were hard to be occupied because of the repulsive forces between the molecules of organic pollutant on adsorbents. The adsorption reached the equilibrium within approximately $60 \mathrm{~min}$ and $50 \mathrm{~min}$ when PAC and $\mathrm{CNZ}$ adsorbents were used with oil removal efficiencies reaching up to $94.8 \%$ and $77.7 \%$ for PAC and CNZ, respectively. The COD removal efficiencies reached up to $87.4 \%$ and $53.18 \%$ for PAC and CNZ, respectively, while the turbidity removal efficiencies reached up to $98.96 \%$ for PAC and $99.53 \%$ for CNZ.

The $\mathrm{pH}$ plays an essential role in the adsorption of oil, COD and turbidity by PAC and CNZ adsorbents, and it affects the surface properties and binding sites present on the surface of the adsorbents (Ibrahim et al. 2009). In this experiment, optimal adsorbent dose was mixed with $100 \mathrm{~mL}$ of $\mathrm{PW}$ at $\mathrm{pH}$ values that ranged from 2 to 10 . The optimal times of 50 and $60 \mathrm{~min}$ were set during the experiments. The desired $\mathrm{pH}$ values of $\mathrm{PW}$ were obtained using $0.1 \mathrm{~N} \mathrm{HCl}$ and $0.1 \mathrm{~N} \mathrm{NaOH}$. In Figure S3, it can be noted that the removal efficiency of pollutants increases with decreasing in the $\mathrm{pH}$. The maximum oil removal was $97.85 \%$ and $83.9 \%$, the COD removal was $93.78 \%$ and $60.12 \%$ and the removal of turbidity was $99.48 \%$ and $99.8 \%$ at $\mathrm{pH}=2$ for PAC and CNZ adsorbents, respectively. High efficiency was obtained at low 
$\mathrm{pH}$; this is due to the electrostatic attractions between the organic pollutants molecules and protonated binding sites on the surface of the adsorbent. This results in high removal efficiency at $\mathrm{pH}=2$ (Chiou and $\mathrm{Li} 2003$ ).

The influences of oil concentrations $\left(C_{o}=50-100 \mathrm{ppm}\right)$ and COD concentrations ( $\left.C_{o}=1357-26,890 \mathrm{ppm}\right)$ on the adsorption of oil and COD and turbidity on PAC and CNZ adsorbents were investigated at the equilibrium time. Figure S4 shows that the oil removal percentage decreased from 99.58 to $80.43 \%$ over PAC and from 84.8 to $71.02 \%$ over CNZ. The COD removal decreased from 95.87 to $67.15 \%$ over PAC and from 63.74 to $29.02 \%$ over CNZ. The turbidity removal decreased from 99.65 to 62.36 and from 99.91 to $73.24 \%$ over PAC and CNZ, respectively. These results refer that the adsorption of pollutants are affected by the concentration because it provides the major driving force to overcome mass transfer limitations between the adsorbent and adsorbate (Younis et al. 2015). At low concentrations, occupation of active binding sites involves adsorption, and it is a quick process, but at high concentrations, the active binding sites became saturated and more mass transfer from the liquid to solid phase happened by valence forces through participation, exchange of electrons and the complex forming which is a relatively slow process (Ho and McKay 1999).

One of the most important factors which could have a significant impact on the oil and COD removal and on decrease in the turbidity from produced water is the temperature. Figure S5 shows that the oil, COD and turbidity removal efficiency increased on increasing the temperature from 15 to $55^{\circ} \mathrm{C}$ at high oil and COD concentrations. The increase in the oil removal percentage is due to the decrease in the viscosity of oil, where with the decreases in oil viscosity, the oil uptake of the sorbent increases (Li. 2013). Furthermore, as the temperature rises, the rate of diffusion of adsorbate molecules across the external boundary layer and into the internal pores of the adsorbent particles increases due to a decrease in solution viscosity. As a result, a change in temperature will alter the adsorbent's equilibrium capacity for a specific adsorbate (Ya-Li et al. 2008). However, at low concentration there was no change in the removal efficiency when the temperature increased because the effect of temperature at low concentration hardly can be observed.

\section{Adsorption isotherm models}

The adsorption isotherm provides a relation between the total mass of adsorbed adsorbate per unit mass of sorbent at constant ambient conditions. In order to develop adsorption isotherms, adsorption experiments were performed. In these experiments, the amount of adsorbent was kept constant, while the initial concentration of the adsorbate was varied. Langmuir adsorption isotherm and Freundlich adsorption isotherm are the most common isotherms which are used for adsorption studies (Metcalf \& Eddy et al. 2003). The equilibrium data were correlated utilized Langmuir Eq. (3), Freundlich Eq. (4) and Temkin Eq. (5) isotherms.

$\frac{C_{e q}}{q_{e}}=\frac{1}{q_{\max }} C_{e q}+\frac{1}{b q_{\max }}$

$\ln q_{e}=\ln K_{f}+\frac{1}{n} \ln C_{e}$

$q_{e}=\frac{R T}{b_{T}} \ln A_{T}+\frac{R T}{b_{T}} \ln C_{e}$

where $q_{e}$ is the amount of the substance adsorbed at equilibrium per amount of adsorbent; $q_{\max }$ is the saturation monolayer adsorption capacity, $C_{e q}$ is the equilibrium concentration, $\mathrm{b}$ is the Langmuir equilibrium adsorption constant, $K_{f}$ and $n$ are the Freundlich constants and $b_{T}$ is the Temkin equilibrium adsorption constant.

The parameters of the isotherm models (Langmuir, Freundlich and Temkin) are given in Table S3. A comparison between the correlation coefficients $\mathrm{R}^{2}$ obtained from Langmuir, Freundlich and Temkin models indicates that the experimental data fit well to the Freundlich model. As well, $0<1 / n<1$ refers that the adsorption of pollutants (oil and COD) by PAC and CNZ is an appropriate process. Similar results have been obtained by Abdelwahab et al. (2021).

\section{Adsorption thermodynamics}

Figure $\mathrm{S} 6$ shows with increasing the temperature that the adsorption capacity of oil and COD by PAC and CNZ increased, demonstrating the adsorption process endothermic nature, which is further illustrated from the calculated positive value of $\Delta H_{o}$. As shown in Table S4, the positive value of $\Delta S_{o}$ indicates the reversible characteristic of the adsorption of oil and COD over PAC and CNZ. $\Delta G_{o}$ values were positive indicating that the adsorption process led to an increase in Gibbs free energy. Positive $\Delta G_{o}$ values of oil and COD over CNZ indicate the non-spontaneity of the adsorption process, and the negative $\Delta G_{o}$ value of oil and COD over PAC indicates the adsorption process was spontaneous.

\section{Analysis of adsorption kinetics}

The kinetics of oil and COD adsorption over PAC and CNZ were studied at $25{ }^{\circ} \mathrm{C}$. The two types of kinetics models, pseudo-first-order and pseudo-second-order, were applied in experiments adsorption to determine the model that fits the data (Febrianto et al. 2009). The linear forms of the equations can be written as in Eqs. (6) and (7). 
$\ln \left(q_{e}-q_{t}\right)=\ln q_{e}-k_{1} t$

$\frac{t}{q_{t}}=\frac{1}{k_{2} q_{e}^{2}}+\frac{t}{q_{e}}$

where $q_{t}$ is the amount of pollutants adsorbed at a given time $(\mathrm{mg} / \mathrm{g}), q_{e}$ is the amount of pollutants adsorbed at equilibrium (mg/g), $k_{1}$ is the rate constant of pseudo-first-order (1/ $\min )$ and $k_{2}$ is the rate constant of pseudo-second-order ( $\mathrm{g} /$ mg min).

Table S5 lists the pseudo-first- and pseudo-second-order kinetic models parameters values from them plots Fig. 8 reveal that the latter model fits the data well as compared to the former model. The $R^{2}$ value for the pseudo-second-order kinetic model was higher than that of pseudo-first-order kinetic model.

\section{The best operational conditions of adsorption for removal oil, turbidity, chemical oxygen demand (COD) and total petroleum hydrocarbon (TPH)}

On the basis of data summarized in Tables S6 and S7, it can be seen that good results were achieved for treatment of PW by monitoring the turbidity, oil, TPH and COD removal efficiencies by using natural and synthetic adsorbents. Tables S6 and S7 show the maximum removal efficiency of oil, COD and TPH by using PAC. At the same time, both types of zeolites exhibited high decrease in turbidity. Furthermore, the zeolites were less effective than PAC for removal of organic pollutants by batch adsorption. The lowest COD removal efficiency was observed over CNZ. Also the concentration of pollutants was within the regulatory limit by using PAC adsorbent. This is due to the difference in the adsorbents surface area. PAC has a larger surface area than the CNZ.

\section{Desorption studies}

The desorption step is deemed one of the most significant features of the adsorption process, which can decrease the cost of the process. Wherefore, adsorbents reuse experiments were conducted. Electric thermal treatment was applied for CNZ and $\mathrm{XSZ}$ at $700{ }^{\circ} \mathrm{C}$, whereas the chemical treatment for PAC was utilized after each run, and then, those were reused in the next run under the same conditions. The results obtained with regenerated and recycled adsorbents are shown in Table S8. This means that adsorbents can be regenerated and reused efficiently.

\section{Conclusions}

Batch adsorption experiments for the adsorption of chemical oxygen demand (COD), oil and turbidity from produced water $(\mathrm{PW})$ have been executed utilizing powdered activated carbon (PAC) and clinoptilolite natural zeolite (CNZ) adsorbents. Batch experiment showed that the oil, COD and turbidity removal efficiencies increase on increasing the contact time, adsorbents dosage and temperature, and decrease with the increase in $\mathrm{pH}$ and initial oil and COD concentrations. The adsorption experiments appeared that Freundlich isotherm model and a pseudosecond-order kinetic model were best fitted for adsorption of oil and COD over adsorbents and have high correlation value. At optimum parameters in adsorption process, the best removal efficiencies of oil, COD, TPH and turbidity were $99.58 \%, 95.87 \%, 99.84 \%$ and $99.65 \%$ over PAC. In case of CNZ, those were $84.8 \%, 63.74 \%, 85.06 \%$ and $99.91 \%$, and in case of XSZ, the values were to $91.08 \%$, $80.32 \%, 93.57 \%$ and $99.97 \%$, respectively. The results show that PAC can be used with higher effectiveness for oil, COD and TPH removal from POW but XSZ exhibited the best efficiency in turbidity reduction. PAC, CNZ and $\mathrm{XSZ}$ can be well regenerated and can be effectively reused for the treatment of PW. Scale-up and pilot plant experiments are required for commercialization of experimental results in order to provide a complete picture of the feasibility of industrial applications.

Supplementary Information The online version contains supplementary material available at https://doi.org/10.1007/s10098-021-02159-z.

Acknowledgements The authors would like to say thanks to the staff of Petroleum Research and Development Center of Oil Ministry of Iraq and the staff of University of Isfahan for their support during conducting this work.

Funding Open access funding provided by University of Pannonia.

\section{Declarations}

Conflicts of Interest All authors, including Eman Hashim Khader, Thamer Jassim Mohammed, Nourollah Mirghaffari, Ali Dawood Salman, Juzsakova Tatjána, Abdullah Adnan Thamer, state that they do not have a conflict of interest.

Open Access This article is licensed under a Creative Commons Attribution 4.0 International License, which permits use, sharing, adaptation, distribution and reproduction in any medium or format, as long as you give appropriate credit to the original author(s) and the source, provide a link to the Creative Commons licence, and indicate if changes were made. The images or other third party material in this article are included in the article's Creative Commons licence, unless indicated otherwise in a credit line to the material. If material is not included in the article's Creative Commons licence and your intended use is not permitted by statutory regulation or exceeds the permitted use, you will 
need to obtain permission directly from the copyright holder. To view a copy of this licence, visit http://creativecommons.org/licenses/by/4.0/.

\section{References}

Abdelwahab NA, Shukry N, El-kalyoubi SF (2021) Separation of emulsified oil from wastewater using polystyrene and surfactant modified sugarcane bagasse wastes blend. Clean Technol Environ Policy 23(1):235-249. https://doi.org/10.1007/s10098-020-01973-1

Alardhi SM, Albayati TM, Alrubaye JM (2020) Adsorption of the methyl green dye pollutant from aqueous solution using mesoporous materials MCM-41 in a fixed-bed column. Heliyon 6(1):e03253. https://doi.org/10.1016/j.heliyon.2020.e03253

Albayati TM, Sabri AA, Abed DB (2020) Functionalized SBA-15 by amine group for removal of $\mathrm{Ni}$ (II) heavy metal ion in the batch adsorption system. Desalin Water Treat 174:301-310

Al-Ghouti MA, Al-Kaabi MA, AshfaqDa'na MYDA (2019) Produced water characteristics, treatment and reuse: a review. J Water Process Eng 28:222-239. https://doi.org/10.1016/j.jwpe. 2019.02.001

Al-Haddad A, Chmielewska E, Al-Radwan S (2007) A brief comparable lab examination for oil refinery wastewater treatment using the zeolitic and carbonaceous adsorbents. Petroleum Coal 49(1):21-26

Babel S, Kurniawan TA (2003) Low-cost adsorbents for heavy metals uptake from contaminated water: a review. J Hazard Mater 97(1-3):219-243. https://doi.org/10.1016/S0304-3894(02) 00263-7

Bailey SE, Olin TJ, Bricka RM, Adrian DD (1999) A review of potentially low-cost sorbents for heavy metals. Water Res 33(11):24692479. https://doi.org/10.1016/S0043-1354(98)00475-8

Bandura L, Panek R, Rotko M, Franus W (2016) Synthetic zeolites from fly ash for an effective trapping of BTX in gas stream. Microporous Mesoporous Mater 223:1-9. https://doi.org/10. 1016/j.micromeso.2015.10.032

Bandura L, Woszuk A, Kołodyńska D, Franus W (2017) Application of mineral sorbents for removal of petroleum substances: a review. Minerals 7(3):37. https://doi.org/10.3390/min7030037

Chiou MS, Li HY (2003) Adsorption behavior of reactive dye in aqueous solution on chemical cross-linked chitosan beads. Chemosphere 50(8):1095-1105. https://doi.org/10.1016/S0045-6535(02) 00636-7

Daoud WY (2020) Using zeolite and granule activated carbon combination for remediating landfill leachate-contaminated groundwater in permeable reactive barriers. Syrian J Agric Res 7(6):183-191

Desta MB (2013) Batch sorption experiments: Langmuir and Freundlich isotherm studies for the adsorption of textile metal ions onto teff straw (Eragrostis tef) agricultural waste. J Thermodyn. https:// doi.org/10.1155/2013/375830

El-Naas MH, Al-Zuhair S, Alhaija MA (2010) Reduction of COD in refinery wastewater through adsorption on date-pit activated carbon. J Hazard Mater 173(1-3):750-757. https://doi.org/10.1016/j. jhazmat.2009.09.002

Fakhru'l-Razi A, Pendashteh A, Abdullah LC, Biak DR, Madaeni SS, Abidin ZZ (2009) Review of technologies for oil and gas produced water treatment. J Hazard Mater 170(2-3):530-551. https://doi. org/10.1016/j.jhazmat.2009.05.044

Febrianto J, Kosasih AN, Sunarso J, Ju YH, Indraswati N, Ismadji S (2009) Equilibrium and kinetic studies in adsorption of heavy metals using biosorbent: a summary of recent studies. J Hazard Mater 162(2-3):616-645. https://doi.org/10.1016/j.jhazmat.2008. 06.042
Guo D, Wang H, Fu P, Huang Y, Liu Y, Lv W, Wang F (2018) Diatomite precoat filtration for wastewater treatment: filtration performance and pollution mechanisms. Chem Eng Res Des 137:403411. https://doi.org/10.1016/j.cherd.2018.06.036

Gupta VK, Mittal A, Jhare D, Mittal J (2012) Batch and bulk removal of hazardous colouring agent Rose Bengal by adsorption techniques using bottom ash as adsorbent. RSC Adv 2(22):8381-8389. https://doi.org/10.1039/C2RA21351F

Hamidpour M, Kalbasi M, Afyuni M, Shariatmadari H, Holm PE, Hansen HC (2010) Sorption hysteresis of Cd (II) and Pb (II) on natural zeolite and bentonite. J Hazard Mater 181(1-3):686-691. https://doi.org/10.1016/j.jhazmat.2010.05.067

Han R, Wang Y, Zou W, Wang Y, Shi J (2007) Comparison of linear and nonlinear analysis in estimating the Thomas model parameters for methylene blue adsorption onto natural zeolite in fixed-bed column. J Hazard Mater 145(1-2):331-335. https://doi.org/10. 1016/j.jhazmat.2006.12.027

Hedar Y (2018) Pollution impact and alternative treatment for produced water. E3S Web Conf 31:03004. https://doi.org/10.1051/ e3sconf/20183103004

Ho YS, McKay G (1999) Pseudo-second order model for sorption processes. Process Biochem 34(5):451-465. https://doi.org/10. 1016/S0032-9592(98)00112-5

Ibrahim S, Ang HM, Wang S (2009) Removal of emulsified food and mineral oils from wastewater using surfactant modified barley straw. Biores Technol 100(23):5744-5749. https://doi.org/10. 1016/j.biortech.2009.06.070

Igunnu ET, Chen GZ (2014) Produced water treatment technologies. Int J Low Carbon Technol 9(3):157-177. https://doi.org/ $10.1093 / \mathrm{ijlct} / \mathrm{cts} 049$

Jhadhav S (2015) Value Added Products from Gasification-Activated Carbon. The Combustion, Gasification and Propulsion Laboratory (CGPL) at the Indian Institute of Science (IISc). Retrieved 30.

Khader EH, Mohammed TH, Mirghaffari N (2018) Use of natural coagulants for removal of COD, oil and turbidity from produced waters in the petroleum industry. J Pet Environ Biotechnol 9(374):3. https://doi.org/10.4172/2157-7463.1000374

Kim S, Cho CW, Song MH, Bediako JK, Yun YS, Choi YE (2018) Potentiometric titration data on the enhancement of sorption capacity of surface-modified biosorbents: functional groups scanning method. Clean Technol Environ Policy 20(10):2191-2199. https://doi.org/10.1007/s10098-018-1542-2

Li J, Luo M, Zhao CJ, Li CY, Wang W, Zu YG, Fu YJ (2013) Oil removal from water with yellow horn shell residues treated by ionic liquid. Biores Technol 128:673-678. https://doi.org/10. 1016/j.biortech.2012.11.009

Malekmohammadi S, Mirbagheri A, Ehteshami M (2016) Comparison of silica, activated carbon, and zeolite adsorbents in the removal of ammonium, iron, COD, turbidity and phosphate pollutants, and investigating the effect of discharge on the removal of pollutants. Int J Humanit Cult Stud 3(2):667-679

Malik PK (2004) Dye removal from wastewater using activated carbon developed from sawdust: adsorption equilibrium and kinetics. $\mathbf{J}$ Hazard Mater 113(1-3):81-88. https://doi.org/10.1016/j.jhazmat. 2004.05.022

McCormack P, Jones P, Hetheridge MJ, Rowland SJ (2001) Analysis of oilfield produced waters and production chemicals by electrospray ionisation multi-stage mass spectrometry (ESI-MSn). Water Res 35(15):3567-3578. https://doi.org/10.1016/S0043-1354(01) 00070-7

Metcalf \& Eddy, Burton FL, Stensel HD, Tchobanoglous G (2003) Wastewater engineering: treatment and reuse. McGraw Hill, United State

Mohan S, Gandhimathi R (2009) Removal of heavy metal ions from municipal solid waste leachate using coal fly ash as an adsorbent. J 
Hazard Mater 169(1-3):351-359. https://doi.org/10.1016/j.jhazm at.2009.03.104

Nekoo SH, Fatemi S (2013) Experimental study and adsorption modeling of COD reduction by activated carbon for wastewater treatment of oil refinery. Iran J Chem Chem Eng 32(3):81-89

Nidheesh PV, Kumar A, Babu DS, Scaria J, Kumar MS (2020) Treatment of mixed industrial wastewater by electrocoagulation and indirect electrochemical oxidation. Chemosphere 251:126437. https://doi.org/10.1016/j.chemosphere.2020.126437

Paliulis D (2016) Removal of formaldehyde from synthetic wastewater using natural and modified zeolites. Pol J Environ Stud 25(1):251-257

Pandey S, Fosso-Kankeu E, Spiro MJ, Waanders F, Kumar N, Ray SS, Kim J, Kang M (2020) Equilibrium, kinetic, and thermodynamic studies of lead ion adsorption from mine wastewater onto MoS2clinoptilolite composite. Mater Today Chem 18:100376. https:// doi.org/10.1016/j.mtchem.2020.100376

Payne KB, Abdel-Fattah TM (2004) Adsorption of divalent lead ions by zeolites and activated carbon: effects of $\mathrm{pH}$, temperature, and ionic strength. J Environ Sci Health Part A 39(9):2275-2291. https://doi.org/10.1081/ESE-200026265

Pirilä M (2015) Adsorption and photocatalysis in water treatment: active, abundant and inexpensive materials and methods. Acta Universitatis Ouluensis, University Of Oulu, Oulu

Quintana JB, Weiss S, Reemtsma T (2005) Pathways and metabolites of microbial degradation of selected acidic pharmaceutical and their occurrence in municipal wastewater treated by a membrane bioreactor. Water Res 39(12):2654-2664. https://doi.org/10. 1016/j.watres.2005.04.068

Rashed MN (2013) Adsorption technique for the removal of organic pollutants from water and wastewater. Org Pollut Monit Risk Treat 7:167-194

Show PL, Thangalazhy-Gopakumar S, Foo DC (2021) Sustainable technologies for waste reduction and pollutants removals. Clean Technol Environ Policy 23(1):1-2. https://doi.org/10.1007/ s10098-020-02001-y

Vega DP, González C, Escalante CA, Gallego J, Salamanca M, Manrique-Losada L (2018) Use of faujasite-type zeolite for ion adsorption in municipal wastewater. Tecnología y Ciencias Del Agua 9(4):184-208. https://doi.org/10.24850/j-tyca-2018-04-08

Wdowin M, Franus M, Panek R, Badura L, Franus W (2014) The conversion technology of fly ash into zeolites. Clean Technol Environ Policy 16(6):1217-1223. https://doi.org/10.1007/ s10098-014-0719-6

Xiao Y, Xu S, Li Z, An X, Zhou L, Zhang Y, Shiang FQ (2010) Progress of applied research on $\mathrm{TiO} 2$ photocatalysis-membrane separation coupling technology in water and wastewater treatments. Chin Sci Bull 55(14):1345-1353. https://doi.org/10.1007/ s11434-010-0171-x

Ya-Li S, Ji-Tai L, Hua C (2008) Removal of acid brown 348 dye from aqueous solution by ultrasound irradiated exfoliated graphite. Indian J Chem Technol 15:443-448

Yang X, Yang S, Yang S, Hu J, Tan X, Wang X (2011) Effect of pH, ionic strength and temperature on sorption of $\mathrm{Pb}$ (II) on NKF-6 zeolite studied by batch technique. Chem Eng J 168(1):86-93. https://doi.org/10.1016/j.cej.2010.12.039

Younis SA, El-Gendy NS, El-Azab WI, Moustafa YM (2015) Kinetic, isotherm, and thermodynamic studies of polycyclic aromatic hydrocarbons biosorption from petroleum refinery wastewater using spent waste biomass. Desalin Water Treat 56(11):30133023. https://doi.org/10.1080/19443994.2014.964331

Zhao S (2015) Enhanced physicochemical processes for the treatment of petroleum-contaminated systems (Doctoral dissertation, Faculty of Graduate Studies and Research, University of Regina).

Zhu G, Fang H, Xiao Y, Hursthouse AS (2020) The application of fluorescence spectroscopy for the investigation of dye degradation by chemical oxidation. J Fluoresc 30(5):1271-1279. https://doi. org/10.1007/s10895-020-02591-2

Publisher's Note Springer Nature remains neutral with regard to jurisdictional claims in published maps and institutional affiliations.

\section{Authors and Affiliations}

\section{Eman Hashim Khader ${ }^{1}$ - Thamer Jassim Mohammed ${ }^{1} \cdot$ Nourollah Mirghaffari $^{1} \cdot$ Ali Dawood Salman $^{1,2}$ (1) Tatjána Juzsakova ${ }^{1}$. Thamer Adnan Abdullah ${ }^{1}$}

Ali Dawood Salman

ali.dawood@mk.uni-pannon.hu

1 Sustainability Solutions Research Lab, University of Pannonia, Veszprém, Hungary
2 Department of Chemical and Petroleum Refining Engineering /College of Oil and Gas Engineering, Basra University, Basra, Iraq 